\title{
A comparative Study of Serum Lipid Levels in Pre- Eclamptic and Normotensive Pregnant Women in a Tertiary Hospital, Northwest Nigeria
}

\author{
Attah Raphael Avidime*, Monsur Adewale Tella, Galadanchi Hadiza and Omole Ohonsi Abiodun \\ Department of Obstetrics and Gynaecology, Bayero University Kano/Aminu Kano Teaching Hospital, Nigeria
}

Received: February 28, 2018; Published: March 12, 2018

*Corresponding author: Attah Raphael Avidime, Department of Obstetrics and Gynaecology, Bayero University / Aminu Kano Teaching Hospital, Kano, Nigeria, Tel: +23480602967224; Email; attahraph@yahoo.com

Abstract

a) Background: Pre-eclampsia is one of the most common complications of pregnancy and a significant cause of morbidity and mortality for both the mother and the fetus, especially in developing countries. Despite considerable research, its cause or causes remain unclear.

b) Objective: To determine any significant association between pre-eclampsia and lipid profile changes.

c) Methodology: A prospective comparative cross-sectional study was carried out among 70 pre-eclamptic and 70 normotensive pregnant women from Aminu Kano Teaching Hospital, Kano. The control subjects were matched to each case for maternal age, gestational age and body mass index. A structured questionnaire was administered and relevant socio-demographic information was obtained. Clinical characteristics including blood pressure were measured and urinalysis performed. Fasting serum lipids were collected and analyzed for total cholesterol, triglyceride, very low density lipo-protein (VLDL), low density lipo-protein(LDL) and high density lipo-protein(HDL)

d) Results: The study showed a significantly higher level of VLDL, LDL and triglyceride among the pre-eclamptic group compared to the normotensive $(\mathrm{P}<0.001)$, while HDL was significantly decreased among the pre-eclamptic group in contrast to the normotensive $(\mathrm{P}=0.028)$. There was statistically significant difference in all the lipid fractions in the 3rd trimester and a significant positive correlation of VLDL and triglyceride with pre-eclampsia $(\mathrm{P}=0.019, \mathrm{P}=0.020$, respectively).

e) Conclusion: This study showed that pre-eclampsia is associated with increased levels of VLDL and triglyceride and decreased levels of HDL and this is more evident in the 3rd trimester. This association may be important in understanding the pathologic processes of the disease and in developing strategies for its prevention and early diagnosis.

Keywords: Pre-Eclampsia; Triglycerides; HDL; LDL; VLDL; Cholesterol

Abbreviations: VLDL: Very Low Density Lipo-Protein; LDL: Low Density Lipo-Protein; HDL: High Density Lipo-Protein; VCAM: Vascular Cell Adhesion Molecules

\section{Introduction}

\section{a) Background}

Pre-eclampsia is a disorder of pregnancy, characterized by new onset of hypertension (systolic and diastolic blood pressure of $\geq$ 140 and $90 \mathrm{mmHg}$, respectively, on two occasions, at least 6 hours apart) and proteinuria (protein excretion of $\geq 300 \mathrm{mg}$ in a $24 \mathrm{hour}$ urine collection, or dipstick of $\geq 2+$ ), that develop after 20 weeks of gestation in a previously normotensive women [1,2]. Despite considerable research, the aetiopathogenesis of pre-eclampsia remain unclear though pathophysiology research suggests that pre-eclampsia is a disease of the placenta characterized by shallow trophoblastic invasion and endothelial dysfunction [3]. However, there are no clinically useful screening tests currently available to identify women in whom it will develop [4]. The hypotheses currently accepted are the placenta ischaemia hypothesis, genetic hypothesis, the immune maladaptation and hypothesis of the imbalance between free oxygen radicals and scavengers in favour of the oxidants [5]. Presently, the most popular theory is that of 
oxidative stress. Abnormal lipid profile and species may have a role in the promotion of oxidative stress and vascular dysfunction seen in pre-eclampsia. Predominantly the atherogenic small low density lipoprotein (LDL) and vascular cell adhesion molecules (VCAM) are increased in association with hyperlipidaemia in pre-eclampsia [5].

The mechanisms involved in the induction of endothelial cell dysfunction are poorly understood. However, the classic pathological lesion seen in the placental bed in pre-eclampsia is 'acute atherosis' resulting from accumulation of lipid laden macrophages surrounded by areas of fibrinoid necrosis in the spiral arteries, features akin to arteriosclerotic changes seen in the vascular bed in non-pregnant population [5,6]. Furthermore, the characteristic lesion in the glomerulus, glomerular endotheliosis, involves accumulation of lipids within the glomerular cells. This accumulation of lipids at sites of endothelial damage emphasizes, perhaps, the potential role of lipids and lipoprotein disturbance in vascular injury in pre-eclampsia in a similar way to the nonpregnant case [6]. Several studies have shown that oxidative stress is predominant in pre-eclampsia and as such the attempt to overcome this allows the body to overwhelm its anti-oxidant capacity $[7,8]$. In pre-eclampsia, oxidative stress is believed to result from increased formation of lipid peroxides, reactive oxygen species and superoxide anion radicals, leading to an imbalance in production between pro-oxidant and anti-oxidant defences. These consequently result in endothelial dysfunction, platelet and neutrophil activation, with altered lipid synthesis towards a decrease in prostaglandin $I_{2}$ and thromboxane $A_{2}$ ratio $[9,10]$.

The resulting imbalance in prostaglandin cascade, leads to enhanced multisystemic vasospasmic phenomenon in kidneys, brain, uterus and placental vessels [11]. The association between alterations in serum lipid profile and pre-eclampsia is a relatively new concept, although there is a pronounced physiological hyperlipidaemia, involving serum levels of triglycerides and cholesterol in normal pregnancy [12]. The lipid pattern in preeclampsia comprising high circulating non-esterified fatty acid, triglycerides, $\mathrm{VLDL}_{1}$, small dense LDL-III and low HDL cholesterol concentration, is highly atherogenic. Studies in the cardiovascular arena offer both direct and indirect associations of this lipid pattern to endothelial damage [13]. Triglyceride-rich particles (VLDL1) may be directly damaging to the endothelium and principally via oxidative mechanism. These particles stimulate endothelial expression of adhesion molecules such as VCAM-1 and the prothrombotic factor PAI-1. Small dense LDL is more susceptible to oxidative damage and can cause direct damage to the endothelium whereas HDL protect the endothelium via its anti-oxidant properties.

During pregnancy, the increased level of oestrogen causes increased hepatic biosynthesis of endogenous triglycerides through VLDL, this process is modulated by hyperinsulinism that starts in pregnancy and may result in endothelial cell damage in pregnancy. The synthesis of nitric oxide (NO), a potent vasodilator, and responsiveness to it are up regulated during normal pregnancy, and have been considered a potential factor involved in the pathogenesis of pre-eclampsia [14]. In pregnancy induced hypertension, serum triglyceride concentration increases much more notably, two or three times more and the triglycerides are likely to be accumulated in vessels like uterine spiral arteries and contribute to endothelial damage by generating small, dense low density lipoprotein particles. This accumulation decreases the release of prostacyclin, resulting in oxidative stress via endothelial dysfunction, a key mechanism in the proposed pathophysiology of pre-eclampsia.

Both increased hepatic triglyceride synthesis and decreased peripheral catabolism could contribute to exaggerated triglyceride rise in pre-eclampsia. Non-esterified fatty acid concentrations rise very early in this disorder, and do so well before clinical manifestations are apparent [15]. This observation suggests that adipocyte lipolysis is stimulated earlier than in normal pregnancy and to a much greater extent. Although there is growing evidence that pre-eclampsia is increased in women with elevated level of oxidized low density lipo-proteins and triglycerides, the causal relationship of lipid peroxidation in the pathogenesis of preeclampsia is still unclear [16]. The role of dyslipidaemia in the pathophysiology of pre-eclampsia has, therefore, stimulated interest. Pre-eclampsia/eclampsia is a common cause of maternal mortality world-wide but particularly in developing countries.

With the only cure for pre-eclampsia being delivery of the infant [17], early recognition of women most at risk for developing the disease and early detection of pre-eclampsia is key to beginning management and treatment that may ultimately decrease both maternal and neonatal morbidity and mortality.4 Therefore, serum lipid levels could serve as a cost effective method for identifying pregnant women at risk of developing pre-eclampsia. Studies have shown that relative to normal pregnancies, women destined to develop pre-eclampsia have marked increases in serum triglycerides and free fatty acid concentration with a shift to smaller, denser, low density lipoprotein [18]. These changes are evident as early as 16-18 weeks gestation [19], well before clinical manifestations are apparent. This implies that early pregnancy dyslipidaemia is associated with an increased risk of pre-eclampsia. Therefore, simple measurement of serum lipid profile may potentially be of good predictive value in pre-eclampsia.

Lipid metabolism has been increasingly postulated to play a key role in the pathophysiology of pre-eclampsia and eclampsia. This association may be significant in understanding the pathologic processes of pre-eclampsia and may help in developing strategies for therapeutic interventions, as well as permit close surveillance and timely intervention. In addition, better understanding of the effects of lipid levels could lead to interventions that will ultimately reduce the incidence of pre-eclampsia. Although several studies have been done on lipid metabolism in normal and pre-eclamptic pregnancies in Europe and USA, very few local studies have focused attention on this important subject, and very little attention has been paid to their clinical correlation. Therefore, the aim of this 
study is to assess the pattern of lipid profile in pre-eclamptic and normotensive pregnant women.

\section{Aim and Objectives}

a) Aim: To assess the pattern of lipid profile in pre-eclamptic and normotensive pregnant women.

\section{b) Objectives:}

i. To estimate serum total cholesterol, triglycerides, high density lipoprotein, low density lipoprotein and very low density lipoprotein cholesterol in pre-eclamptic and normotensive pregnant women

ii. To compare the serum levels of lipid in pre-eclampsia and normotensive pregnant women

iii. To evaluate the correlation between serum lipid levels and the severity of pre-eclampsia

\section{Materials and Methods}

a) Study Area: This study was conducted in Aminu Kano teaching hospital, which is a 500-bedded hospital and one of the tertiary health facilities in Kano. It comprises 13 departments including obstetrics and gynaecology. The department of obstetrics and gynaecology runs nine out-patient clinics in a week. The antenatal clinics operate on Mondays, Tuesdays, Wednesdays and Thursdays from 8.00 am to $1.00 \mathrm{pm}$. The booking clinic is held on every antenatal clinic and an average of 100 patients is seen daily. Kano state is located in the northwestern part of Nigeria with a landmass of 20,680 square kilometers [20]. It borders Katsina to the north-west, Jigawa state to the north east, Bauchi state to the south east and Kaduna state to the south west. It has a population of 9.4 million people and female constitute 4,453,336 which is approximately $49 \%$ of the population [21]. The annual growth rate of Kano is 3.3\% while the total fertility rate and contraceptive use are $6.8 \%$ and $1 \%$ respectively $[21,22]$. The inhabitants are predominantly Hausa.

b) Study Design: It was a comparative cross-sectional study of pregnant women receiving antenatal care at Aminu Kano Teaching Hospital.

c) Study Population: This comprised pregnant women attending antenatal clinic, those on admission in antenatal ward and labour ward of Aminu Kano Teaching Hospital.

d) Inclusion Criteria: This comprised all consenting pregnant women with preeclampsia (cases) and normotensive pregnant women (control) that were at gestational age of 20 weeks or more. Pre-eclampsia was defined as blood pressure elevation of at least 140/90 $\mathrm{mmHg}$ taken on at least two occasions at least six hours apart, in combination with significant proteinuria after 20 weeks gestation in previously normotensive, non-proteinuric patients. The diagnosis of significant proteinuria was based on urine dip stick of at least $2+$. A blood pressure measurement of at least $160 \mathrm{mmHg}$ systolic and $110 \mathrm{mmHg}$ diastolic pressure together with significant proteinuria was considered severe pre-eclampsia.

e) Exclusion Criteria: Patients with chronic hypertension, multiple gestation, previous history of renal disease, liver disease, cardiac disease, known history of dyslipidaemia, obesity, and those on drugs that may affect lipid metabolism were excluded. Those who declined to give consent were also excluded.

f) Determination of sample size: The sample size was determined using the formula [23] below

$$
N=\left(Z_{\alpha}+Z_{1-\beta}\right)^{2}\left(\sigma_{1}+\sigma_{2}\right)
$$

Where:

$$
\left(\mu_{1}-\mu_{2}\right)^{2}
$$

$\mathrm{N}=$ minimum sample size required in each group.

$\mathrm{Z} \alpha=$ Standard normal deviate corresponding to $5 \%$ level of significance $=1.96$ (obtained from normal distribution table)

$\mathrm{Z}_{1-\beta}=$ Standard normal deviate corresponding to a power of $80 \%=0.84$ (obtained from normal distribution table)

$\sigma_{1}=$ Standard deviation of serum lipids among patients with severe pre-eclampsia from a previous study73 $(37.89 \mathrm{mg} / \mathrm{dl})$

$\sigma_{2}=$ Standard deviation of serum lipids among controls from a previous study [24] $(35.33 \mathrm{mg} / \mathrm{dl})$

$\mu_{1}=$ The mean of serum lipids among patients with severe preeclampsia from a previous study [24]

\section{$(121.09 \mathrm{mg} / \mathrm{dl})$}

$\mu_{2}=$ The mean of serum lipid among controls from a previous study24 (124.18mg/dl)

$$
=\frac{N=(1.96+0.84)^{2}(37.89+35.33)}{(121.09-124.18)^{2}}
$$

Minimum sample size in each group)

To allow for attrition, $10 \%$ of the sample size was added (6)

Therefore, 70 patients per group was recruited for the study

g) Patient selection: The subjects studied were recruited from antenatal clinic, antenatal ward and labour ward of Aminu Kano Teaching Hospital, Kano. Each of the groups was recruited consecutively by a non-probability convenience sampling method. This entailed recruiting patients with pre-eclampsia consecutively as they present at the antenatal clinic, labour ward and antenatal ward. A control group of normotensive patients matched for age and parity was similarly recruited. The purpose of the study was explained to the subjects and written consent was obtained from those willing to participate in the study.

A pre-tested, structured, interviewer-administered questionnaire was used to obtain information on age, parity, 
educational status, past medical history, drug history, gestational age, maternal weight and height. Blood pressure and urinalysis were also recorded. The questionnaire was administered by the author and 2 trained residents from the department of obstetrics and gynaecology. An average of 100 patients is seen daily at the antenatal clinic with an average of 3-5 cases of pre-eclampsia. All the subjects in each of the two groups were recruited over a sixweek period. Patients with severe pre-eclampsia were admitted, stabilized and managed according to the departmental protocol, with preparation for delivery.

Intravenous access was secured and blood was drawn from the antecubital vein for lipid profile, full blood count including platelets, electrolytes, urea and creatinine, liver function test, bed side clotting time. Seizure prophylaxis was instituted with magnesium sulphate and blood pressure control was achieved with intravenous hydrallazine. Those with mild pre-eclampsia were treated on outpatient basis with regular follow-up visits. Patients with high serum lipid levels were contacted and referred to the cardiologists for appropriate management.

h) Measurements: Measurement of blood pressure was done in sitting position, twice and at least 6 hours apart using mercury sphygmomanometer with a cuff that was large enough for the subject's arm, and a stethoscope on the left upper arm after the subject must have been sitting for at least 5 minutes. Korotkoff phase 5 was used to detect diastolic blood pressure. The following reference ranges for lipid profile from Aminu Kano Teaching hospital were adopted: total cholesterol 2.5 $6.4 \mathrm{mmol} / \mathrm{L}$, Triglycerides 0.5 - $2.8 \mathrm{mmol} / \mathrm{L}$, HDL cholesterol 0.8 - 2.6mmol/L and LDL cholesterol $0.8-4.3 \mathrm{mmol} / \mathrm{L}$.

i) Sample Collection and Biochemical Analysis of Serum Lipid Profiles: Five milliliter of fasting venous blood sample was collected aseptically from the antecubital vein from all the subjects using sterile disposable $5 \mathrm{ml}$ syringe. Each of the samples was transferred immediately into an appropriately labeled plain bottle container and was allowed to clot at room temperature. The samples were centrifuged at 4000 revolutions per minute (rpm) for 10 minutes and each serum sample separated was transferred into a new appropriately labeled sample container and stored frozen until the time for analysis. The biochemical analysis was done for total cholesterol (TC), triglycerides (TG), high density lipoprotein (HDL) and low density lipoprotein (LDL) using enzymatic colorimetric method. Cobass C111 Autoanalyser machine was used to run the blood samples. The low density lipoprotein was calculated using Friederickson- Friedwald's formula:

LDL cholesterol $(\mathrm{mmol} / \mathrm{L})=\mathrm{TC}-(\mathrm{TG} / 2.2+\mathrm{HDL})$

j) Statistical Analysis: The data was analyzed using Epi-info version 3.5.4 from CDC Atlanta Georgia. Categorical variables were expressed as absolute numbers and percentages, and significant differences determined using Chi-square test. The continuous variables were presented as means and standard deviations, and significant differences determined with the student t- test. A one-way ANOVA was used to test for the differences in the means of three groups while Spearman's correlation was used to find a correlation between the lipid fractions and pre-eclampsia. P-value $<0.05$ was considered statistically significant.

k) Ethical Consideration: Approval for the study was obtained from Aminu Kano Teaching Hospital ethical committee.

1) Study Limitations: A non-probability convenience sampling method was used and this has the potential for selection bias in an attempt to match the case and the control. It is difficult to establish whether the relationship between serum lipid levels and pre-eclampsia is a cause or effect of the disease.

\section{Results}

Table 1: Socio-demographic and clinical characteristics of the subjects studied.

\begin{tabular}{|c|c|c|c|c|}
\hline Characteristics & $\begin{array}{c}\text { Pre-eclamptic Patients } \\
\mathbf{n = 7 0 ~ F r e q ~ ( \% ) ~}\end{array}$ & $\begin{array}{c}\text { Normotensive } \mathbf{n = 7 0 ~ F r e q ~} \\
\mathbf{( \% )}\end{array}$ & Student t-test & P-Value \\
\hline Age (years) & & & & \\
\hline$<20$ & $18(25.71)$ & $20(28.57)$ & & \\
\hline $20-24$ & $27(38.57)$ & $11(15.71)$ & & \\
\hline $25-29$ & $8(11.43)$ & $10(14.29)$ & & \\
\hline $30-34$ & $8(11.43)$ & $7(10)$ & & 0.541 \\
\hline $35-39$ & $9(12.86)$ & $24.83 \pm 6.18$ & & \\
\hline Mean age(years) & $24.19 \pm 6.35$ & & & \\
\hline Parity & & $34(48.57)$ & & \\
\hline Primigravidae & $6(72.86)$ & $26(37.14)$ & & \\
\hline $1-4$ & $13(18.57)$ & $10(14.29)$ & & $>0.05$ \\
\hline$\geq 5$ & & & & \\
\hline
\end{tabular}




\begin{tabular}{|c|c|c|c|c|}
\hline $\begin{array}{c}\text { Mean body mass index } \\
\left(\mathrm{Kg} / \mathrm{m}^{2}\right)\end{array}$ & $24.87 \pm 1.77$ & $24.35 \pm 6.18$ & 1.87 & 0.064 \\
\hline Gestational age (weeks) & & & & \\
\hline $20-26$ & $6(8.6)$ & $4(5.7)$ & & \\
\hline$\geq 27$ & $64(91.4)$ & $66(94.3)$ & 1.50 & 0.136 \\
\hline Mean gestational age & $35.87 \pm 2.58$ & $35.29 \pm 2.00$ & 19.80 & $<0.001$ \\
\hline SBP(mmHg) & $166.3 \pm 20.2$ & $111.9 \pm 11.1$ & 22.34 & $<0.001$ \\
\hline DBP(mmHg) & $106.9 \pm 12.9$ & $67.42 \pm 7.16$ & 22.52 & $<0.001$ \\
\hline MABP(mmHg) & $126.70 \pm 14.40$ & $82.29 \pm 8.00$ & & \\
\hline
\end{tabular}

Table 1 shows the socio-demographic and clinical characteristics of the subjects studied. The age range of the participants was 18-39years, and the age group with the highest frequency was 2024 in both pre-eclamptic and normotensive groups, accounting for $27(38.57 \%)$ and $22(31.43 \%)$ respectively. The mean age of the pre-eclamptic group was $24.19 \pm 6.35$ years while that of the normotensive group was $24.83 \pm 6.18$ years $(\mathrm{P}=0.541)$. There was no statistically significant difference in the mean ages of the two groups. Table 1 also shows the parity distribution of the participants. Table 2: Mean Lipid Levels among women under study.
In the pre-eclamptic group, 51(72.86\%) were nullipara, $6(8.57 \%)$ were multipara and $13(18.57 \%)$ were grandmultipara. In the normotensive group, 34(48.57\%) were nullipara, 26(37.14\%) were multipara while $10(14.29 \%)$ were grandmultipara. There was no statistically significant difference in the parity distribution of the two groups (X2 $=7.168, \mathrm{P}>0.05)$. There were $6(8.6 \%)$ of the pre-eclamptic group in the $2^{\text {nd }}$ trimester and $64(91.4 \%)$ in the $3^{\text {rd }}$ trimester. In the normotensive group, $4(5.7 \%)$ were in the 2 nd trimester while $66(94.3 \%)$ were in the $3^{\text {rd }}$ trimester.

\begin{tabular}{|c|c|c|c|c|}
\hline Parameters & Pre-eclamptic n= 70 & Normotensive n= 70 & Student t-test & P-value \\
\hline HDL(mmol/L) & $1.29 \pm 0.34$ & $1.44 \pm 0.47$ & 2.23 & 0.028 \\
\hline VLDL(mmol/L) & $0.55 \pm 0.25$ & $0.36 \pm 0.11$ & 5.72 & $<0.001$ \\
\hline LDL(mmol/L) & $3.72 \pm 1.05$ & $2.75 \pm 0.94$ & 5.74 & 0.180 \\
\hline $\begin{array}{c}\text { Total cholesterol } \\
\text { (mmol/L) }\end{array}$ & $6.51 \pm 1.62$ & $6.18 \pm 1.24$ & 1.35 & $<0.001$ \\
\hline Triglyceride(mmol/L) & $2.75 \pm 1.25$ & $1.81 \pm 0.55$ & 5.78 & \\
\hline
\end{tabular}

The mean gestational age of the pre-eclamptic group was 35.87 \pm 2.58 weeks while that of the normotensive group was $35.29 \pm$ 2.00 weeks. There was no statistically significant difference in the gestational ages $(\mathrm{t}=1.50, \mathrm{P}=0.136)$. The mean body mass index for the case and control group was $24.19 \pm 6.35 \mathrm{Kg} / \mathrm{m} 2$ and 24.35 $\pm 1.55 \mathrm{Kg} / \mathrm{m} 2$ respectively $(\mathrm{P}=0.064)$. Table 2 shows the mean serum lipid levels among the case and control group. The mean serum levels of triglycerides, LDL and VLDL were $2.75 \pm 1.25,3.72$ \pm 1.05 and $0.55 \pm 0.25 \mathrm{mmol} / \mathrm{L}$ respectively in the pre-eclamptic group while their levels in the control group were $1.81 \pm 0.55,2.75$ \pm 0.94 and $0.36 \pm 0.11 \mathrm{mmol} / \mathrm{L}$ respectively. The serum levels of triglycerides, LDL and VLDL were significantly higher in the preeclamptic group $(\mathrm{P}<0.001)$. The mean serum levels of HDL in preeclamptic group $(1.29 \pm 0.34 \mathrm{mmol} / \mathrm{L})$ compared with the control $(1.44 \pm 0.47 \mathrm{mmol} / \mathrm{L})$ was significantly lower in the pre-eclamptic group $(\mathrm{t}=2.23, \mathrm{P}=0.028)$.

Table 3: The relationship of mean lipid levels and severity of Pre-eclampsia

\begin{tabular}{|c|c|c|c|c|}
\hline Parameters & Mild Pre-eclamptic n = 19 & $\begin{array}{c}\text { Severe Pre-eclampsia n } \\
\mathbf{5 1}\end{array}$ & Student t-test & P-value \\
\hline HDL(mmol/L) & $1.54 \pm 0.44$ & $1.18 \pm 0.45$ & 3.03 & 0.005 \\
\hline VLDL(mmol/L) & $0.42 \pm 0.27$ & $0.60 \pm 0.23$ & -2.57 & 0.016 \\
\hline LDL(mmol/L) & $3.52 \pm 0.98$ & $3.79 \pm 1.08$ & -1.02 & 0.313 \\
\hline Total cholesterol (mmol/L) & $5.68 \pm 1.63$ & $6.83 \pm 1.52$ & -2.67 & 0.012 \\
\hline Triglyceride(mmol/L) & $2.11 \pm 1.33$ & $2.99 \pm 1.14$ & -2.56 & 0.016 \\
\hline
\end{tabular}

In contrast, the mean serum levels of total cholesterol in the pre-eclamptic group $(6.51 \pm 1.62 \mathrm{mmol} / \mathrm{L})$ were higher compared with the normotensive $(6.18 \pm 1.24 \mathrm{mmol} / \mathrm{L})$. There was, however, no statistically significant difference between them $(\mathrm{t}=1.35, \mathrm{P}$ $=0.180$ ). Table 3 shows the relationship of mean serum lipid levels with the severity of pre-eclampsia. The mean serum levels of total cholesterol in subjects with severe pre-eclampsia $(6.83 \pm$
$1.52 \mathrm{mmol} / \mathrm{L}$ ) was higher than in subjects with mild pre-eclampsia $(5.68 \pm 1.63 \mathrm{mmol} / \mathrm{L})$ and this was statistically significant $(\mathrm{t}=$ $-2.67, \mathrm{P}=0.012$ ). Similarly, in severe pre-eclampsia, the serum levels of triglycerides and VLDL were $2.99 \pm 1.14 \mathrm{mmol} / \mathrm{L}$ and $0.60 \pm 0.23 \mathrm{mmol} / \mathrm{L}$ respectively while in mild pre-clampsia, the serum levels of triglycerides and VLDL were $2.11 \pm 1.33 \mathrm{mmol} / \mathrm{L}$ and $0.42 \pm 0.27 \mathrm{mmol} / \mathrm{L}$ respectively. There was statistically significant 
difference in their levels respectively ( $\mathrm{t}=-2.56,0.016),(\mathrm{t}=-$ $2.57,0.016)$. Conversely, the mean serum levels of HDL in severe pre-eclampsia $(1.18 \pm 0.45 \mathrm{mmol} / \mathrm{L})$ were lower than in mild preeclampsia $(1.54 \pm 0.44 \mathrm{mmol} / \mathrm{L})$.

This was statistically significant $(\mathrm{t}=3.03, \mathrm{P}=0.005)$. The serum levels of LDL in severe and mild pre-eclampsia (3.79 \pm 1.08 VS 3.52 \pm 0.98 ) were not significantly different $(t=-1.02, P=0.313)$. Table 4 shows the mean serum lipids of the subjects according to the severity of pre-eclampsia compared with the normotensive. The mean serum levels of HDL in normotensive, mild pre-eclampsia and severe pre-eclampsia were $1.29 \pm 0.34 \mathrm{mmol} / \mathrm{L}, 1.54 \pm 0.44 \mathrm{mmol} / \mathrm{L}$ and $1.18 \pm 0.45 \mathrm{mmol} / \mathrm{L}$ respectively. There was statistically significant difference in the 3 groups using a one way ANOVA ( $F$ $=8.28, \mathrm{P}<0.001$ ). Similarly, the mean serum levels of VLDL in normotensive, mild pre-eclampsia and severe pre-eclampsia were $0.36 \pm 0.11 \mathrm{mmol} / \mathrm{L}, 0.42 \pm 0.27 \mathrm{mmol} / \mathrm{L}$ and $0.60 \pm 0.23$. There was a statistically significant difference in the groups using a one way ANOVA ( $F=24.24, \mathrm{P}<0.001)$. The mean serum levels of LDL, triglyceride and total cholesterol were also significantly different among normotensive, mild pre-eclampsia and severe pre-eclampsia using a one way ANOVA $(\mathrm{P}<0.001)$.

Table 4: mean serum lipids of the subjects according to the severity of pre-eclampsia compared with the normotensive.

\begin{tabular}{|c|c|c|c|c|c|}
\hline Parameters & Normotensive $\mathbf{n}=\mathbf{7 0}$ & $\begin{array}{c}\text { Mild Pre-eclampsia } \\
\mathbf{n = 1 9}\end{array}$ & $\begin{array}{c}\text { Severe Pre-eclampsia } \\
\mathbf{n = 5 1}\end{array}$ & F & P-value \\
\hline HDL(mmol/L) & $4.88 \pm 1.14$ & $1.54 \pm 0.44$ & $1.18 \pm 0.45$ & 8.28 & $<0.001$ \\
\hline VLDL(mmol/L) & $0.36 \pm 0.11$ & $0.42 \pm 0.27$ & $0.60 \pm 0.23$ & 24.24 & $<0.001$ \\
\hline LDL(mmol/L) & $2.75 \pm 0.94$ & $3.52 \pm 0.98$ & $3.79 \pm 1.08$ & 30.09 & $<0.001$ \\
\hline $\begin{array}{c}\text { Total } \\
\text { cholesterol(mmol/L) }\end{array}$ & $4.88 \pm 1.14$ & $5.68 \pm 1.63$ & $6.83 \pm 1.52$ & 24.35 & $<0.001$ \\
\hline Triglyceride (mmol/L) & $1.81 \pm 0.55$ & $2.11 \pm 1.33$ & $2.99 \pm 1.14$ & $<0.001$ \\
\hline
\end{tabular}

Table 5: Mean lipid levels in pre-eclamptic and normotensive subjects in the 2nd trimester.

\begin{tabular}{|c|c|c|c|c|}
\hline Parameters & Pre-eclampsia $n=6$ & Normotensive $n=4$ & T-value & P-Value \\
\hline HDL(mmol/L) & $1.22 \pm 0.42$ & $1.52 \pm 0.35$ & -1.24 & 0.253 \\
\hline VLDL(mmol/L) & $0.57 \pm 0.24$ & $0.39 \pm 0.08$ & 1.71 & 0.139 \\
\hline $\mathrm{LDL}(\mathrm{mmol} / \mathrm{L})$ & $3.68 \pm 1.37$ & $2.48 \pm 0.85$ & 1.71 & 0.130 \\
\hline Total cholesterol (mmol/L) & $6.73 \pm 1.81$ & $4.87 \pm 0.93$ & 2.13 & 0.071 \\
\hline Triglyceride(mmol/L) & $2.83 \pm 1.20$ & $1.92 \pm 0.39$ & 1.74 & 0.133 \\
\hline
\end{tabular}

Table 5 shows the mean serum lipid levels in pre-eclamptic and normotensive groups in the second trimester. There was no statistically significant difference between the two groups. Table 6 shows the mean serum lipid levels in pre-eclamptic and normotensive groups in the 3rd trimester. There was statistically significant difference in all the lipid fractions between the normotensive and pre-eclamptic groups. Table 7 shows the correlation between serum lipids and pre-eclampsia using Pearson's correlation coefficient. The study showed that triglycerides and VLDL had significant positive correlation with pre-eclampsia $(\mathrm{P}$ $=0.020, \mathrm{P}=0.019$ ) respectively. There was a negative correlation between HDL and pre-eclampsia, although this was not statistically significant $(\mathrm{P}=0.912)$. There was no significant correlation with the other lipids.

Table 6: Mean lipid levels in Pre-eclamptic and normotensive subjects in the 3rd trimester.

\begin{tabular}{|c|c|c|c|c|}
\hline Parameters & Pre-eclampsia $\mathbf{n}=\mathbf{6 4}$ & Normotensive $\mathbf{n}=\mathbf{6 6}$ & T-value & P-Value \\
\hline HDL(mmol/L) & $1.27 \pm 0.33$ & $1.46 \pm 0.47$ & -2.67 & 0.009 \\
\hline VLDL(mmol/L) & $0.55 \pm 0.25$ & $0.36 \pm 0.11$ & 5.46 & $<0.001$ \\
\hline LDL(mmol/L) & $3.72 \pm 1.03$ & $2.76 \pm 0.95$ & 5.49 & $<0.001$ \\
\hline Total cholesterol (mmol/L) & $6.49 \pm 1.62$ & $4.89 \pm 1.16$ & 6.50 & $<0.001$ \\
\hline Triglyceride(mmol/L) & $2.75 \pm 1.26$ & $1.80 \pm 0.56$ & 5.47 & $<0.001$ \\
\hline
\end{tabular}

Table 7: The correlation between lipid levels and Pre-eclampsia using Pearson's correlation coefficient.

\begin{tabular}{|c|c|c|}
\hline Lipid fraction & Pearson's correlation coefficient & P-Value \\
\hline HDL(mmol/L) & -0.013 & 0.912 \\
\hline VLDL(mmol/L) & 0.279 & 0.019 \\
\hline LDL(mmol/L) & 0.057 & 0.637 \\
\hline Total cholesterol (mmol/L) & 0.235 & 0.050 \\
\hline Triglyceride $(\mathrm{mmol} / \mathrm{L})$ & 0.278 & 0.020 \\
\hline
\end{tabular}




\section{Discussion}

The results of this study showed that there is no statistically significant difference in the socio-demographic characteristics of the participants in the two groups. This shows that the two groups are similar and thus eliminates confounders that may have arisen from these socio-demographic variables. Most of the women in the pre-eclamptic group were primigravidae in keeping with the fact that hypertensive disorder in pregnancy is more common in first pregnancy [25]. The study also showed significantly higher levels of serum triglycerides in women with pre-eclampsia compared with normotensive women. This is in agreement with studies done by other researchers [26-30]. However, other studies have found no significant difference in the levels of triglycerides between preeclamptic and normotensive [26,31]. These varying findings may be due to difference in study design and adjustment for confounders such as age, BMI and parity.

It is worthy of note that relative to normal pregnancies, women with pre-eclampsia have marked increases in serum triglycerides $[32,33]$. The principal modulator of this hypertriglyceridaemia is oestrogen as pregnancy is associated with hyperoestrogenaemia. Oestrogen induces hepatic biosynthesis of endogenous triglycerides which is carried by VLDL [34]. It is, therefore, thought that the increased triglyceride found in pre-eclampsia is likely to be deposited in predisposed vessels. The rise in this serum lipid parameter is susceptible to bio-oxidation which may cause increased oxidative stress, generate free radicals, contribute to endothelial damage and propagate the pathogenesis of preeclampsia [35]. This damage usually begins as placental vascular disorder involving the placental spiral arteries and subsequent thrombosis which triggers endothelial dysfunction [35]. Some studies have shown that the most dramatic damage in the lipid profile of pregnancy is serum hypertriglyceridaemia which is even higher in toxaemia of pregnancy [36]. The LDL levels among preeclamptic women were also significantly higher compared to the normotensive group. Other workers also reported similar findings [37] Some studies, however, reported significantly lower levels of LDL among the cases [38,39] This may be due to differences in study population and study design.

Hypertriglyceridaemia affects the pattern of lipoproteins by increasing the activity of cholesterol ester transfer protein, an enzyme that transfers triglycerides from VLDL to HDL, and cholesterol esters in the opposite direction [40]. This causes HDL to become enriched with triglycerides and VLDL with cholesterol. The latter are more atherogenic and tend to form small and dense low LDL which have tendency to infiltrate the intima of the arterial walls, exhibit oxidation potential and reduced receptor binding [40]. Once oxidized, these particles are believed to be highly atherogenic, promoting foam cell formation through interaction with scavenger receptor on macrophages, and initiating endothelial dysfunction.41 Scavenger receptors metabolise modified lipoproteins and are the main way in which cholesterol is incorporated into atheromatous plaques [41]. LDL also inhibits the production of vasodilator agents such as prostacycline and nitric oxide and promotes the production of vasoconstrictor agents such as thromboxane and endothelin- 1 in the vascular endothelium.

The free oxygen radicals, in addition, to their effects on the serum lipids also cause endothelial damage with fibrinoid degeneration of the vascular endothelium. Conversely in this study, the serum levels of HDL were significantly lower in the pre-eclamptic group compared to the control group. This finding is similar to that of Vanderjagt et al. $[12,26,27,29]$ It is , however, not consistent with the findings by Chanvitya et al [30]; Zinat et al [31] who find a significantly higher level of HDL among the cases. This may be due to differences in races and nutrition. This may be explained by the fact that HDL with large triglyceride content is more easily removed by hepatic lipase which reduces its plasma levels and thus predisposes to atherosclerosis. This is because HDL plays a role in the reverse transport of potentially reactive hydro peroxides species for hepatic detoxification [41]. Hence, the higher cardiovascular risk in patients with low serum HDL levels.

In this study, the serum levels of triglycerides, VLDL and total cholesterol were significantly higher in severe pre-eclampsia in comparison with mild pre-eclampsia. There was no statistically significant difference in the other lipid parameters between mild and severe pre-eclampsia. This is similar to the findings by Cong et al. [42]; Mikhail et al [43] on the other hand found no direct relationship between triglycerides levels and severity of preeclampsia. Kokia et al. [44] found that triglycerides and LDL levels were significantly higher in severe pre-eclampsia. This suggests that as the disease progresses from mild to severe form, there is worsening derangement in the lipid pattern and consequently increased endothelial damage. The study also revealed that triglycerides, VLDL, LDL and total cholesterol levels were significantly higher in the pre-eclamptic group compared to the normotensive group in the third trimester.

In contrast, serum levels of HDL were significantly lower in the pre-eclamptic group. There was, however, no statistically significant difference in all the lipid fractions between the two groups in the second trimester. This may be because of the effect of oestrogen on hepatic synthesis of cholesterol which increases as pregnancy advances. The higher concentration of cholesterol at this period may explain why pre-eclampsia is commoner in the third trimester. Pearson's correlation coefficient in the study confirms the inverse relationship between HDL and pre-eclampsia and the direct relationship of VLDL and triglyceride with pre-eclampsia. This is similar to the findings by Onyiriuka et al. [45]. This may be because oxidized HDL prevents the formation of foam cells and atherosclerosis in the intima of the blood vessels and stimulate the production of vasodilator prostaglandins over vasoconstrictor prostaglandins.

\section{Conclusion}

Patients with pre-eclampsia have increased levels of triglycerides and VLDL and decreased levels of HDL when 
compared with the normotensive group. The levels of triglycerides and VLDL tend to increase as the disease progresses from mild to severe while HDL levels decrease. The study also indicates that lipid derangement occurs more in the third trimester. Hence, lipids play an important role in the aetiopathogenesis of pre-eclampsia. This association could help in developing strategies for prevention and early diagnosis of the disorder, and ultimately help to improve maternal and fetal outcome in patients with pre-eclampsia.

\section{Recommendations}

There are abundant links connecting lipid changes in preeclampsia with oxidative stress and endothelial dysfunction. Therefore, a large scale multicentre study will be required to further understand the role of dyslipidaemia in the mechanism underlying endothelial dysfunction in pre-eclampsia. Markers of lipid peroxidation may be further evaluated in order to determine their predictive role in identifying patients at high risk of developing pre-eclampsia.

\section{References}

1. Redman CW, Sargent IL (2005) Latest advances in understanding pre-eclampsia. Science 308(5728): 1592-1594.

2. Sibai B, Dekker G, Kupferminc M (2005) pre-eclampsia. Lancet 365(946): 785-799.

3. Raymond D, Peterson E (2011) A critical review of early onset and late onset pre-eclampsia. Obstet gynecol surv 66(8): 497-506.

4. Solomon CG, Seely EW (2004) Pre-eclampsia-searching for the cause. N Engl J of Med 350(7): 641-642.

5. Johil JT, Patel PK, Gupta priyanka (2011) Estimation of Lipid Profile in subjects of pre-eclampsia. J Obstet Gynecol India 61(4): 399- 403.

6. Sattar N, Gaw A, Packard CJ, Greer IA (1996) Potential pathogenic roles of aberrant lipoprotein and fatty acid metabolism in pre-eclampsia. $\mathrm{Br}]$ Obstet Gynecol 103(7): 614-620.

7. Raijmakers MT, Dechend R, Poston L (2004) Oxidative stress and pre-eclampsia: rationale for anti-oxidant clinical trials. Hypertension 44(4): 374-380.

8. Poston L, Chappell L, Seed P, Shennan A (2011) Biomarkers of oxidative stress in pre-eclampsia. Pregnancy Hypertension 1(1): 22-27.

9. Roberts JM, Taylor RN, Musci TJ, Rodgers GM, Hubel CA, et al. (1989) Pre-eclampsia: An Endothelial Cell Disorder. Am J Obstet Gynecol 161(5): 1200-1204.

10. Roberts JM, Hubel CA (2004) Oxidative stress in Pre-eclampsia. Am J Obstet Gynaecol 190(5): 1177-1178.

11. Baden A, Ritchie J, Walters B, Michael C, Rivera J, et al. (2001) Study of Plasma Factors Associated with Neutrophil Activation and Lipid Peroxidation in pre-eclampsia. Hypertension 38(4): 8003-8008.

12. Zinat B, Iffat A, Shah ABS (2011) Association between lipid profile and Pre-eclampsia. Ibrahim card Med J 1(1): 41-44.

13. Sattar N, Pettrie JR, Jaap AJ (1998) The atherogenic lipoprotein phenotype and vascular endothelial dysfunction. Atherosclerosis 138(2): 229235.

14. Buhimschi IA, Saade GR, Chwalisz K, Garfield RE (1998) The nitric oxide pathway in pre-eclampsia: pathophysiological implications. Hum Reprod update $4(1): 25-42$.

15. Lorentzen B, Enderson MJ, Clausen T, Henriksen T (1994) Fasting serum free fatty acids and triglycerides are increased before 20 weeks of gesta- tion in women who later develop pre-eclampsia. Hypertens Pregnancy 13: 103-109.

16. Hubel CA, Roberts JM (1996) Hyperuricaemia and xanthine oxidase in pre-eclampsia revisited. Am J Obstet Gynecol 174: 288-291.

17. Hubel CA (1999) Oxidative stress in the pathogenesis of pre-eclampsia. Proceedings of the society for experimental biology and medicine. Proc Soc Exp Biol Med 222(3): 222-235.

18. Brown MC, Best KE, Pearse MC, Waugh J, Robson SC, et al. (2013) Cardiovascular disease risk in women with pre-eclampsia: systematic review and meta-analysis. Eur J epid 28(1):1-19.

19. Lorentsen B, Henriksen T (1998) Plasma lipids and vascular dysfunction in pre-eclampsia. Semin Reprod. Endocrinol 16(1): 33-39.

20. National population commission (1991) Landmass compiled from NPC report, 1991 and field reports. Abuja, Nigeria.

21. United Nations Population Funds. UNFPA in Kano State.

22. National Population Commission (2013) Nigeria Demographic Health Survey 2013. Abuja: Nigeria.

23. Florey CD (1993) Sample size for beginners. BMJ 306: 1181-1184.

24. Irinyenikan TA, Arowojolu A, Olayemi O (2014) Comparative study of serum lipid levels in normotensive and pre-eclamptic Nigerian women. Int J Med Biomed Res 3(2): 137-145.

25. Waugh JJS, Smith MC. Hypertensive disorders in pregnancy. In: Edmunds DK (Eds.). Dewhurt's Textbook of Obstetrics and Gynaecology $\left(8^{\text {th }}\right.$ edn). Wiley Blackwell, London, UK, pp. 101-103.

26. Abubakar A, Mabrouk M, Girei AB, Ahmed MK (2011) Lipid profiles and platelet counts of pre-eclamptic women in selected rural areas of Nigeria. Web Med Central Physiology 2(8): WMC002121.

27. Islam NAF, Chodwury MAR, Kibria GM, Akter S (2010) Study of serum lipid profile in pre-eclampsia and eclampsia. Faridpur Med Coll J 5(2): 56-59.

28. Musa AH, Mairiga AG, Jimeta AA, Daja A (2014) Lipid profile pattern of pre-eclamptic and eclamptic patients attending University of Maiduguri Teaching Hospital. Gynaecol Obstet (Sunnyvale) 4: 217-201.

29. Musleh UK, Nabila K, Farah M (2012) Pre-eclampsia and Lipid levels- a case control study. Int J Collab Res Int Med Public health 4: 1738-1744.

30. Vanderjagt DJ, El Nafaty AU, Melah GS (2004) High density lipoprotein and homocysteine levels correlate inversely in pre-eclamptic women in Northern Nigeria. Acta Obstet Gynaecol scand J 83: 536-542.

31. Chanvitya P, Boonsri K (2008) Comparative study of serum lipid concentrations in pre-eclampsia and normal pregnancy. J Med Assoc Thai 91(7): 957-961.

32. Ray JG, Diamond P, Singh G, Bell CM (2006) Brief overview of maternal triglycerides as a risk factor for pre-eclampsia. BJOG 113(4): 379-386.

33. Kalar MU, Kalar N, Mansoor F, Malik AR, Lessley T, et al. (2012) Pre-eclampsia and lipid levels- a case control study. Int J Collab Res Internal Med Public Health 4(10): 1738-1745.

34. Glueck CJ, Pallet RW, Scheel D (1975) Effects of estrogenic compounds on triglyceride kinetics. Metabolism 24(4): 537-545.

35. Nyam YE, Anzaku AS, Gamece MI, Haruna DP (2014) A study of maternal serum lipids in pregnancies complicated by pre-eclampsia in a cohort of Nigerian women. Science Research 2(6): 150-154.

36. Walker JJ (2000) Severe pre-eclampsia and eclampsia. Bailliere's Clin Obstet Gynaecol 14(1): 57-71.

37. Islam NAF, Chodwury MAR, Kibria GM, Akter S (2010) Study of serum lipid profile in pre-eclampsia and eclampsia. Faridpur Med Coll J 5(2): 56-59. 
38. Reyes L, Garcia R, Ruiz S, Dehghan M, Lopez Jaramillo P (2012) Nutritional status among women with pre-eclampsia and healthy pregnant and non-pregnant women in a Latin American country. The Journal of obstetrics and gynaecology research 38(3): 498-504.

39. Reyes LM, Garcia RG, Ruiz SL (2012) Risk factors for preeclampsia in women from Colombia: a case-control study. PloS one 7(7): e41622.

40. Soca PEM, Ojeda LS, del Toro IC (2013) Dyslipidemia in pre-eclampsia syndrome. Cor Salud 5(2): 221-225.

41. Sattar N, Greer IA (1999) Lipids and the pathogenesis of pre-eclampsia. Current Obstetrics and Gynaecology 9(4): 190-195.

42. Cong KJ, Wang TT, Lin GR (1994) Lipid metabolism and pregnancy induced Hypertension. Chung Hua-Fu-Chan-Ko-Tsa-Chih 29(11): 561-563.
43. Mikhail MS, Basu J, Palan PR, Furgiusle J, Romney SL, Anyaegbunam A (1995) Lipid profile in women with pre-eclampsia: relationship between plasma triglyceride levels and severity of pre-eclampsia. J Assoc Acad Minor Phys 6(1): 43-45.

44. Kokia E, Barkai G, Reichman B, Segal P, Goldman B, et al. (1990) Maternal serum lipid profile in pregnancies complicated by hypertensive disorders. J Perinat Med 18(6): 473-478.

45. Onyiriuka AN, Okolo AA (2004) Perinatal outcome in patients with pre-eclampsia in Benin city, Nigeria. Trop J Obstet Gynecol 21(2): 148152 .
(C) This work is licensed under Creative

Submission Link: https://biomedres.us/submit-manuscript.php

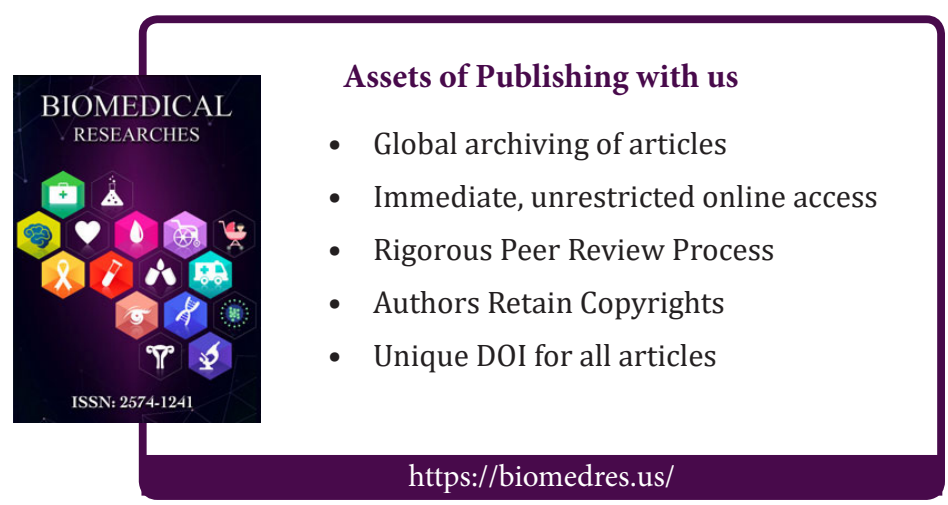

